\title{
Total NT-proBNP, a novel biomarker related to recurrent atrial fibrillation
}

Lidia Staszewsky ${ }^{1 *+}$, Jennifer M. T. A. Meessen ${ }^{1 \dagger}$, Deborah Novelli ${ }^{1}$, Ursula-Henrike Wienhues-Thelen ${ }^{2}$, Marcello Disertori ${ }^{3}$, Aldo P. Maggioni ${ }^{4}$, Serge Masson ${ }^{5}$, Gianni Tognoni ${ }^{6}$, Maria Grazia Franzosi ${ }^{1}$,

Donata Lucci ${ }^{4}$ and Roberto Latini ${ }^{1}$

\begin{abstract}
Background: Novel circulating biomarkers may help in understanding the underlying mechanisms of atrial fibrillation (AF), a challenge for AF management and prevention of cardiovascular (CV) events. Whether glycosylation affects the prognostic value of $\mathrm{N}$-terminal pro-B type natriuretic peptide (NT-proBNP) in AF is still unknown.

Objectives: To test how deglycosylated total NT-proBNP, NT-proBNP and a panel of biomarkers are associated with: (1) recurrent $A F$, (2) first hospitalization for $C V$ reasons.

Methods: A total of 382 patients of the GISSI-AF trial in sinus rhythm with a history of AF, echocardiographic variables, total NT-proBNP, NT-proBNP and nine additional biomarkers [Total N-terminal pro-B type natriuretic peptide (Total NT proBNP), N-terminal pro-B type natriuretic peptide (NTproBNP), Angiopoietin 2 (Ang2), Bone morphogenic protein-10 (BMP10), Dickkopf-related protein-3 (DKK3), Endothelial cell specific molecule-1 (ESM1), Fatty acidbinding protein 3 (FABP3), Fibroblast growth factor 23 (FGF23), Growth differentiation factor-15 (GDF15), Insulin-like growth factor-binding protein-7 (IGFBP7) and Myosin binding protein C3 (MYPBC3)]. were assayed at baseline, 6 and 12 months under blind conditions in a laboratory at Roche Diagnostics, Penzberg, Germany. The associations between circulating biomarkers and AF at the 6- and 12-month visits, and their predictive value, were assessed in multivariable models with logistic regression analysis and Cox proportional hazards regression analysis. Biomarkers associations were modelled for 1SD increase in their level.
\end{abstract}

Results: Over a median follow-up of 365 days, 203/382 patients (53.1\%) had at least one recurrence of AF and 16.3\% were hospitalized for CV reasons. Total NT-proBNP, NT-proBNP, Ang2 and BMP10 showed the strongest associations with ongoing AF. Natriuretic peptides also predicted recurrent AF (total NT-proBNP: HR:1.19[1.04-1.36], $p=0.026$; NTproBNP: HR:1.19[1.06-1.35], $p=0.016$; Ang2: HR:1.07[0.95-1.20], $p=0.283$; BMP10: HR:1.09[0.96-1.25], $p=0.249$ ) and CV hospitalization (total NT-proBNP: HR:1.57[1.29-1.90], $p<0.001$ 1.63], $p=0.097$ ).

Conclusions: The association of total NT-proBNP with the risk of AF first recurrence was similar to that of NT-proBNP, suggesting no influence of glycosylation. Analogous results were obtained for the risk of first hospitalization for CV reasons. Natriuretic peptides, Ang2 and BMP10 were associated with ongoing AF. Findings from the last two

\footnotetext{
*Correspondence: lidia.staszewsky@marionegri.it

${ }^{\dagger}$ Lidia Staszewsky and Jennifer M. T. A. Meessen have equally contributed

to data analysis and interpretation.

${ }^{1}$ Department of Cardiovascular Medicine, Istituto Di Ricerche

Farmacologiche Mario Negri IRCCS, Via Mario Negri 2, 20156 Milan, Italy

Full list of author information is available at the end of the article
}

(c) The Author(s) 2021. Open Access This article is licensed under a Creative Commons Attribution 4.0 International License, which permits use, sharing, adaptation, distribution and reproduction in any medium or format, as long as you give appropriate credit to the original author(s) and the source, provide a link to the Creative Commons licence, and indicate if changes were made. The images or other third party material in this article are included in the article's Creative Commons licence, unless indicated otherwise in a credit line to the material. If material is not included in the article's Creative Commons licence and your intended use is not permitted by statutory regulation or exceeds the permitted use, you will need to obtain permission directly from the copyright holder. To view a copy of this licence, visit http://creativecommons.org/licenses/by/4.0/. The Creative Commons Public Domain Dedication waiver (http://creativeco mmons.org/publicdomain/zero/1.0/) applies to the data made available in this article, unless otherwise stated in a credit line to the data. 
biomarkers point to a pathogenic role of cardiac extracellular matrix and cardiomyocyte growth in the myocardium of the right atrium and ventricle.

Keywords: Atrial fibrillation, biomarkers, Brain natriuretic peptides, Recurrence, Cardiovascular hospitalization

\section{Background}

Knowledge about atrial fibrillation (AF) has been steadily increasing over the last two decades together with the awareness that this arrhythmia is an important health problem [1]. Clinical and bio-humoral markers associated with AF increase our understanding of its mechanisms and may help in predicting the risk of recurrence of AF [2,3]. Previous data from GISSIAF trial and also from other authors showed that circulating biomarkers are associated to AF but are not strong predictors for AF recurrence in patients in sinus rhythm with a recent history of paroxysmal or persistent AF [4-6].

$\mathrm{N}$-terminal pro-B type natriuretic peptide (NTproBNP) has been regularly reported to be a strongpossibly the strongest-predictor of recurrent AF among several novel circulating biomarkers, as recently pointed out in the Framingham Heart Study [7]; however, its predictive power is still modest.

NT-proBNP and BNP are produced in equimolar amounts in cardiomyocytes in response to increased wall stretch, volume overload and ischemia (6-8); BNP but not NT-proBNP has physiological activity. There are nine known $\mathrm{O}$-glycosylation sites on proBNP and NT-proBNP. On average, $7.4 \%$ of circulating NTproBNP in HF patients is glycosylated in the central region of the molecule [11]. Commercial NT-proBNP ELISA contains antibodies directed to epitopes in the central region of NT-proBNP and detects non-glycosylated forms. Thus the assay underestimates the circulating concentrations of NT-proBNP when these sites are glycosylated [12,13], and this may have different impacts on NT-proBNP's performance as a biomarker in different pathologies [11].

The subgroup of patients in the bio-humoral substudy of GISSI-AF $[14,15]$ was deemed adequate to test independently two features of an exploratory panel of nine circulating biomarkers, deglycosylated total NTproBNP and NT-proBNP in AF: (1) the association of a biomarker with AF, when a blood sample is taken at the 6- or 12-month visit while AF is present in the electrocardiogram (ECG), and (2) the predictive power of the same biomarker at baseline, when the patient is in sinus rhythm, for recurrence of AF or incident hospitalization for CV reasons. We focused on total NT-proBNP to assess whether glycosylation influences its prognostic accuracy.

\section{Methods}

The GISSI-AF trial (Clinical Trials.gov identifier: NCT00376272; EudraCT Number: 2004-003036-53) was a double-blind randomized placebo-controlled multicenter trial in 114 cardiology divisions between November 2004-January 2007 that enrolled, 1442 patients in sinus rhythm with a history of AF (two or more episodes of symptomatic ECG-documented AF in the previous 6 months) or successful cardioversion, electrical or pharmacologic, between 14 days and $48 \mathrm{~h}$ before randomization). A routine clinical examination, including ECG and laboratory testing, was done at each study visit (baseline, weeks 2, 4, 8, 24 and 52). To increase the likelihood of detecting AF, all patients were given a trans-telephonic monitoring device (see Additional file 1: Appendix 1). Each AF episode during the trial was adjudicated blindly by a central reader and verified by an ad-hoc validation committee. The rationale, design, and results of the trial have already been published [14, 15]. Patients from 36 centers participated in a sub-study with serial biohumoral tests at baseline, 6 and 12 months.

Ongoing AF is defined as the presence of AF rhythm in a 12- lead electrocardiogram recorded during the scheduled 6 or 12- month follow-up visit, during which a blood sample was drawn to assess circulating biomarkers. AF recurrence is defined as an episode of AF detected by telemonitoring or during the scheduled follow-up visits. In the first this case the patient was asked to come for an office visit to confirm the arrhythmia by a 12-lead ECG (see also Additional file 1: Appendix 1 Detection of recurrent $\mathrm{AF}$ during follow-up).

\section{Assays of circulating biomarkers and detection of AF recurrence}

The following biomarkers were included in the analyses: total $\mathrm{N}$-terminal pro-B type natriuretic peptide (total NT proBNP), N-terminal pro-B type natriuretic peptide (NT-proBNP), angiopoietin 2 (Ang2), bone morphogenic protein-10 (BMP10), Dickkopf-related protein-3 (DKK3), endothelial cell specific molecule-1 (ESM1), fatty acid-binding protein 3 (FABP3), fibroblast growth factor 23 (FGF23), growth differentiation factor-15 (GDF15), insulin-like growth factor-binding protein-7 (IGFBP7), and myosin binding protein C3 (MYPBC3). The characteristics of the biomarkers (e.g. an exploratory analysis of nine circulating biomarkers, total NT-proBNP and NT-proBNP), are described in Additional file 1: 
Table 1 Biomarker concentrations at each study visit and lower limit of quantification and detection

\begin{tabular}{|c|c|c|c|c|c|c|c|c|c|c|c|}
\hline Biomarker & Visit & $\mathbf{n}$ & Mean & Std Dev & Median & Q1 & Q3 & Min & Max & LoQ & LoD \\
\hline \multirow{3}{*}{$\begin{array}{l}\text { Total NT proBNP * } \\
\mathrm{pg} / \mathrm{mL}\end{array}$} & $B L$ & 376 & 1727 & 1712 & 1230 & 667 & 2011 & 75 & 12,700 & \multirow[t]{3}{*}{$8.3 \mathrm{pg} / \mathrm{mL}$} & \multirow[t]{3}{*}{$6.52 \mathrm{pg} / \mathrm{mL}$} \\
\hline & $6 M$ & 321 & 1494 & 1611 & 985 & 507 & 1959 & 34 & 12,626 & & \\
\hline & $12 \mathrm{M}$ & 323 & 1672 & 1825 & 1008 & 564 & 2112 & 62 & 11,992 & & \\
\hline \multirow[t]{3}{*}{ NT-proBNP (pg/mL) } & $\mathrm{BL}$ & 382 & 344.6 & 496.3 & 191.0 & 95.0 & 367.0 & 5.0 & 4347 & \multirow{3}{*}{$\begin{array}{l}50 \\
\mathrm{pg} / \mathrm{mL} \#\end{array}$} & \multirow{3}{*}{$\begin{array}{l}10 \\
\mathrm{pg} / \mathrm{mL} \# \#\end{array}$} \\
\hline & $6 M$ & 325 & 278.6 & 414.5 & 136.0 & 66.0 & 324.0 & 5.0 & 3906 & & \\
\hline & $12 \mathrm{M}$ & 331 & 328.0 & 555.9 & 149.0 & 63.0 & 350.0 & 5.0 & 6345 & & \\
\hline \multirow{3}{*}{$\begin{array}{l}\text { Ang2* } \\
\mathrm{ng} / \mathrm{mL}\end{array}$} & $\mathrm{BL}$ & 379 & 3.44 & 1.95 & 2.91 & 2.21 & 3.99 & 0.73 & 15.04 & \multirow[t]{3}{*}{$0.058 \mathrm{ng} / \mathrm{mL}$} & \multirow[t]{3}{*}{$0.028 \mathrm{ng} / \mathrm{mL}$} \\
\hline & $6 \mathrm{M}$ & 324 & 2.85 & 1.34 & 2.49 & 2.01 & 3.19 & 1.01 & 10.14 & & \\
\hline & $12 \mathrm{M}$ & 329 & 2.88 & 1.31 & 2.56 & 2.02 & 3.28 & 1.16 & 10.09 & & \\
\hline \multirow{3}{*}{$\begin{array}{l}\mathrm{BMP} 10 * \\
\mathrm{ng} / \mathrm{mL}\end{array}$} & $\mathrm{BL}$ & 375 & 2.09 & 0.52 & 2.02 & 1.75 & 2.33 & 1.14 & 5.04 & \multirow[t]{3}{*}{$0.009 \mathrm{ng} / \mathrm{mL}$} & \multirow{3}{*}{$\begin{array}{l}0.003 \\
\mathrm{ng} / \mathrm{mL}\end{array}$} \\
\hline & $6 \mathrm{M}$ & 321 & 2.05 & 0.47 & 2.01 & 1.75 & 2.28 & 1.16 & 4.76 & & \\
\hline & $12 \mathrm{M}$ & 327 & 2.09 & 0.50 & 2.00 & 1.74 & 2.34 & 1.15 & 4.54 & & \\
\hline \multirow{3}{*}{$\begin{array}{l}\text { DKK3 * } \\
\mathrm{ng} / \mathrm{mL}\end{array}$} & $\mathrm{BL}$ & 377 & 59.87 & 15.37 & 57.5 & 49.3 & 68.7 & 27.1 & 142.6 & \multirow[t]{3}{*}{$0.025 \mathrm{ng} / \mathrm{mL}$} & \multirow{3}{*}{$\begin{array}{l}0.003 \\
\mathrm{ng} / \mathrm{mL}\end{array}$} \\
\hline & $6 M$ & 321 & 57.83 & 14.42 & 55.8 & 48.2 & 64.0 & 28.7 & 118.7 & & \\
\hline & $12 \mathrm{M}$ & 324 & 59.51 & 16.47 & 57.5 & 48.6 & 66.2 & 26.8 & 136.9 & & \\
\hline \multirow{3}{*}{$\begin{array}{l}\mathrm{ESM1} * \\
\mathrm{ng} / \mathrm{mL}\end{array}$} & $\mathrm{BL}$ & 377 & 2.23 & 1.01 & 2.02 & 1.65 & 2.55 & 0.87 & 9.17 & \multirow[t]{3}{*}{$<0.003 \mathrm{ng} / \mathrm{mL}$} & \multirow[t]{3}{*}{$0.001 \mathrm{ng} / \mathrm{mL}$} \\
\hline & $6 M$ & 321 & 2.04 & 0.65 & 1.94 & 1.62 & 2.33 & 0.97 & 5.65 & & \\
\hline & $12 \mathrm{M}$ & 324 & 2.13 & 0.70 & 1.99 & 1.64 & 2.47 & 0.85 & 5.68 & & \\
\hline \multirow{3}{*}{$\begin{array}{l}\mathrm{FABP} 3 * \\
\mathrm{ng} / \mathrm{mL}\end{array}$} & $\mathrm{BL}$ & 375 & 30.98 & 10.96 & 29.2 & 24.2 & 35.3 & 12.1 & 105.3 & \multirow[t]{3}{*}{$1.0 \mathrm{ng} / \mathrm{mL}$} & \multirow[t]{3}{*}{ n.a } \\
\hline & $6 M$ & 321 & 33.17 & 11.17 & 31.2 & 25.7 & 38.8 & 11.6 & 86.7 & & \\
\hline & $12 \mathrm{M}$ & 327 & 34.80 & 12.13 & 33.1 & 26.2 & 40.1 & 15.0 & 91.4 & & \\
\hline \multirow{3}{*}{$\begin{array}{l}\mathrm{FGF} 23 \text { * } \\
\mathrm{pg} / \mathrm{mL}\end{array}$} & $\mathrm{BL}$ & 374 & 0.14 & 0.10 & 0.11 & 0.09 & 0.15 & 0.01 & 0.87 & \multirow[t]{3}{*}{$0.004 \mathrm{ng} / \mathrm{mL}$} & \multirow[t]{3}{*}{ n.a } \\
\hline & $6 M$ & 321 & 0.14 & 0.09 & 0.11 & 0.09 & 0.15 & 0.01 & 0.92 & & \\
\hline & $12 \mathrm{M}$ & 322 & 0.14 & 0.10 & 0.12 & 0.09 & 0.15 & 0.03 & 0.94 & & \\
\hline \multirow{3}{*}{$\begin{array}{l}\text { GDF15 } \\
\mathrm{pg} / \mathrm{mL}\end{array}$} & $\mathrm{BL}$ & 375 & 1272 & 793 & 1053 & 745 & 1523 & 235 & 7059 & \multirow[t]{3}{*}{$\leq 400 \mathrm{pg} / \mathrm{mL}$} & $\leq 400 \mathrm{pg} / \mathrm{mL}$ \\
\hline & $6 \mathrm{M}$ & 321 & 1344 & 1136 & 1080 & 794 & 1518 & 317 & 12,471 & & \\
\hline & $12 \mathrm{M}$ & 327 & 1355 & 965 & 1140 & 808 & 1555 & 369 & 9783 & & \\
\hline IGFBP7 * & $\mathrm{BL}$ & 379 & 178 & 44 & 172 & 152 & 194 & 97 & 685 & $0.4 \mathrm{ng} / \mathrm{mL}$ & $0.01 \mathrm{ng} / \mathrm{mL}$ \\
\hline $\mathrm{ng} / \mathrm{mL}$ & $6 M$ & 324 & 179 & 48 & 170 & 154 & 191 & 80 & 705 & & \\
\hline & $12 \mathrm{M}$ & 329 & 184 & 49 & 174 & 157 & 199 & 91 & 701 & & \\
\hline MYBPC3 * & $\mathrm{BL}$ & 373 & 5.63 & 6.33 & 3.69 & 2.29 & 6.35 & 0.34 & 48.48 & 2.1 & $0.458 \mathrm{pg} / \mathrm{mL}$ \\
\hline $\mathrm{ng} / \mathrm{mL}$ & $6 \mathrm{M}$ & 321 & 4.86 & 6.31 & 3.18 & 1.98 & 5.42 & 0.29 & 66.73 & $\mathrm{pg} / \mathrm{mL}$ & \\
\hline & $12 \mathrm{M}$ & 327 & 4.98 & 5.91 & 3.10 & 1.91 & 5.95 & 0 & 47.05 & & \\
\hline
\end{tabular}

NT-proBNP_N-terminal pro-B type natriuretic peptide; Ang2-angiopoietin 2; BMP10—bone morphogenic protein-10; DKK3-Dickkopf-related protein-3; ESM1— endothelial cell specific molecule 1; FABP3 - fatty acid-binding protein 3; FGF23 - fibroblast growth factor 23; GDF15-growth differentiation factor-15; IGFBP7insulin-like growth factor-binding protein-7; MyBPC3 - myosin binding protein C3. Reference value: NT-proBNP, $125 \mathrm{pg} / \mathrm{mL}$; GDF15, > 1500 ng/mL (arbitrary value suitable for GISSI-AF population). * Research Use Only (RUO) assays without full in vitro diagnostic (IVD) documentation, reference value not available. LoQ, lower limit of quantification; LoD, lower limit of detection. \#, LoQ - $20 \%$ CV at $\leq 50 \mathrm{pg} / \mathrm{mL}$ C; \#\#, $10 \mathrm{pg} / \mathrm{mL}$ (specification) on cobas e 411 , cobas e 601 , cobas e 602 ;

Appendix 2 Assays of circulating biomarkers and detection of recurrent AF during follow-up, and detectability in Table 1.

Per protocol, for handling and processing the samples were left in the local lab for up to $1 \mathrm{~h}$ before freezing at $-70{ }^{\circ} \mathrm{C}$. Samples stored locally were transferred to the core lab every year.

Biomarkers were assayed under blind conditions in a laboratory at Roche Diagnostics, Penzberg, Germany. Total NT-proBNP (Roche Diagnostics GmbH, Mannheim) was measured on a Cobas Elecsys
Immunoanalyzer with a prototype sandwich immunoassay for use in exploratory research. This detects any NT-proBNP that is not O-glycosylated (position S44). The lower limit of detection is $6.5 \mathrm{pg} / \mathrm{mL}$; within-run and between-run precisions are $\leq 1.2 \%$ and $\leq 2.5 \%$.

\section{Statistical methods}

Primary objective of this study is to evaluate whether deglycosylated total NT-proBNP, NT-proBNP and other nine circulating biomarkers are associated to AF, both ongoing or recurrent; the secondary endpoint is 
the relationship with first hospitalization for cardiovascular reasons. Continuous variables are expressed as mean \pm SD if normally distributed or median and interquartile range [IQR] if not normally distributed; categorical variables were reported as absolute numbers and percentages. Differences between groups of patients with and without ongoing or recurrent AF were assessed with one-way ANOVA, Kruskal-Wallis test or $\chi^{2}$ test, as appropriate. The correlations between circulating biomarkers were analyzed with Spearman's rank correlation coefficient.

The association of each biomarker with ongoing $\mathrm{AF}$ at the follow-up visit was assessed on the basis of the area under the curve (AUC) of ROC analysis, followed by logistic regression analysis adjusted for variables significantly associated with AF in univariate analysis: heart failure, LVEF $<40 \%$ or both, history of hypertension, AF episode with LA dilatation, and oral anticoagulant use. Biomarkers which had an AUC $<70 \%$ and were not independently associated with ongoing atrial fibrillation were then excluded from further analyses except BMP10. This biomarker was carried included in the analyses after an authoritative study on its mechanistic involvement in the pathophysiology of AF and its specific production by atrial tissue [16]

Kaplan-Meier curves and log-rank tests were used to assess differences in the AF recurrence-free survival according to biomarker baseline values above or below the median. Biomarkers were modelled as continuous variables (expressed as $1 \mathrm{SD}$ increment) as linearity was tested by restricted cubic splines. Cox proportional univariable and adjusted hazard models were constructed to assess the prediction of AF recurrence. Cardiovascular hospitalization was predicted similarly. Cox analyses were adjusted for covariates selected on the basis of univariate analysis; for AF recurrence, sex and two or more episodes of AF in the six months before inclusion in GISSI-AF. For cardiovascular hospitalization, systolic blood pressure, history of hypertension, peripheral artery disease and smoking. The c-index derived from the multivariable models was used to assess the improvement in the prognostic model including either Total NT-proBNP or NT-proBNP in the adjusted model. Comparisons between the areas under the ROC curves were performed with the use of U-statistics [17]. All probability values are two-tailed and p-values were corrected for multiple testing by means of the False Discovery Rate (FDR-correction). A $p<0.05$ was considered significant. Data were analyzed using SPSS Version 25 (IBM SPSS, Armonk, NY) and SAS Version 9.4.

\section{Results}

Patients

The study comprised 382 patients, and 1038 plasma samples were analyzed (baseline, 382; six-month follow-up 325 ; 12-month follow-up 331). The baseline characteristics of this population were similar to those of the 1442 patients enrolled in the main GISSI-AF study [15]. In brief, age was $67.6 \pm 9.1$ years, $142(37.2 \%)$ were women; $154(40.8 \%)$ had had two or more episodes of AF in the previous 6 months and $336(88.0 \%)$ had undergone cardioversion for $\mathrm{AF}$ in the previous two weeks. There was a history of hypertension in $324(84.8 \%)$, history of stroke $15(3.9 \%)$, and heart failure (HF) or $\mathrm{LVEF}<40 \%$ in $42(11.0 \%)$. The study treatment, valsartan, was given to 186 patients (48.7\%), ACE-inhibitors to 206 (53.9\%), beta-blockers to $114(29.8 \%)$ and aldosterone blockers to 20 (5.2\%) (Additional file 1: Table 1 Baseline clinical, eletrocardiographic and echocardiograpic characteristics of all patients and according to ongoing $\mathrm{AF}$ and $\mathrm{AF}$ recurrence).

During follow-up (median 365 days, range 5-373 days), $203(53.1 \%)$ patients had at least one newly diagnosed episode of AF and 113 (29.6\%) had more than one. The median number of episodes of recurrent AF per patient was 3 (range 2-27). During the one-year follow-up one patient died, and the incidence of hospitalization was $18.7 \%$ for any reason and $16.3 \%$ for CV reasons. As there were no significant differences between valsartan and placebo for any of the circulating biomarkers and echocardiographic variables, the whole cohort of 382 patients was analyzed, irrespective of the treatment.

\section{Plasma concentrations of circulating biomarkers at baseline and during follow-up}

Concentrations of total NT-proBNP and the other biomarkers at baseline and at each visit are shown in Table 1; medians were within the reference range except for total NT-proBNP and NT-pro BNP, where the levels were above the normal range. Median concentrations of all biomarkers were either stable or decreased slightly over the 12-month follow-up. Linear correlations between different biomarkers showed $\mathrm{r}$ values ranging from 0.90 for total NT-proBNP-NT-proBNP, to 0.11 for Ang2FABP2 (Additional file 1: Table 2 Correlation coefficients for biomarker concentrations at baseline).

\section{Association between circulating biomarkers and ongoing $\mathrm{AF}$}

At 6- and 12-months follow-up, respectively 34/325 (10.5\%) and 45/331 (13.6\%) patients had ongoing AF in the 12-lead ECG. Concentrations of total NT-proBNP, NT-proBNP, Ang2, BMP10, DKK3, FGF23 and MyBPC3 were significantly higher in those with $\mathrm{AF}$ at both visits. 
Table 2 Concentrations of circulating biomarkers in patients with sinus rhythm or with atrial fibrillation recorded by ECG during scheduled visits at 6 and 12 months

\begin{tabular}{|c|c|c|c|c|c|c|c|c|}
\hline Biomarker & Visit & Rhythm & $n$ & Median & IQR & AUC & $95 \% \mathrm{Cl}$ & $P_{f d r}$ \\
\hline \multirow{4}{*}{$\begin{array}{l}\text { Total NT-proBNP } \\
(\mathrm{pg} / \mathrm{mL})\end{array}$} & \multirow[t]{2}{*}{6 months } & Sinus & 280 & 865 & [484-1720] & \multirow[t]{2}{*}{0.777} & \multirow[t]{2}{*}{$(0.682-0.871)$} & \multirow[t]{2}{*}{$6.1 \times 10^{-6}$} \\
\hline & & $\mathrm{AF}$ & 34 & 2532 & [1504-4692] & & & \\
\hline & \multirow[t]{2}{*}{12 months } & Sinus & 268 & 878 & [476-1809] & \multirow[t]{2}{*}{0.772} & \multirow[t]{2}{*}{$(0.705-0.838)$} & \multirow[t]{2}{*}{$3.0 \times 10^{-7}$} \\
\hline & & $\mathrm{AF}$ & 45 & 2241 & [1381-4032] & & & \\
\hline \multirow[t]{4}{*}{ NT-proBNP (pg/mL) } & \multirow[t]{2}{*}{6 months } & Sinus & 284 & 128.0 & [55.3-238.5] & \multirow[t]{2}{*}{0.866} & \multirow[t]{2}{*}{$(0.785-0.947)$} & \multirow[t]{2}{*}{$3.3 \times 10^{-10}$} \\
\hline & & $\mathrm{AF}$ & 34 & 724.5 & [435.8-1311.8] & & & \\
\hline & \multirow[t]{2}{*}{12 months } & Sinus & 276 & 116.5 & [54.0-242.5] & \multirow[t]{2}{*}{0.862} & \multirow[t]{2}{*}{$(0.806-0.918)$} & \multirow[t]{2}{*}{$1.5 \times 10^{-12}$} \\
\hline & & AF & 45 & 580.0 & [306.0-1180.0] & & & \\
\hline \multirow{4}{*}{$\begin{array}{l}\text { Ang2 } \\
\text { (ng/mL) }\end{array}$} & \multirow[t]{2}{*}{6 months } & Sinus & 284 & 2.44 & [1.95-3.03] & \multirow[t]{2}{*}{0.726} & \multirow[t]{2}{*}{$(0.636-8.16)$} & 0.001 \\
\hline & & $\mathrm{AF}$ & 34 & 3.27 & [2.38-4.95] & & & \\
\hline & 12 months & Sinus & 274 & 2.39 & [1.94-3.07] & 0.816 & $(0.754-0.877)$ & $8.8 \times 10^{-10}$ \\
\hline & & AF & 45 & 3.75 & [2.96-5.18] & & & \\
\hline BMP10 & 6 months & Sinus & 281 & 1.97 & [1.72-2.23] & 0.710 & $(0.611-0.810)$ & $2.8 \times 10^{-4}$ \\
\hline (ng/mL) & & AF & 33 & 2.31 & {$[2.04-2.67]$} & & & \\
\hline & 12 months & Sinus & 273 & 1.97 & [1.73-2.27] & 0.634 & $(0.537-0.731)$ & 0.007 \\
\hline & & $\mathrm{AF}$ & 44 & 2.18 & [1.91-2.65] & & & \\
\hline DKK3 & 6 months & Sinus & 280 & 55.25 & [47.27-63.06] & 0.640 & $(0.541-0.738)$ & 0.013 \\
\hline (ng/mL) & & $\mathrm{AF}$ & 34 & 59.94 & [53.64-78.79] & & & \\
\hline & 12 months & Sinus & 269 & 46.45 & [48.20-64.09] & 0.648 & $(0.558-0.737)$ & 0.002 \\
\hline & & AF & 45 & 62.66 & [53.99-77.87] & & & \\
\hline ESM1 & 6 months & Sinus & 280 & 1.92 & {$[1.61-2.31]$} & 0.601 & $(0.490-713)$ & 0.067 \\
\hline (ng/mL) & & $\mathrm{AF}$ & 34 & 2.07 & [1.71-2.88] & & & \\
\hline & 12 months & Sinus & 269 & 1.96 & {$[1.61-2.38]$} & 0.623 & $(0.532-0.714)$ & 0.013 \\
\hline & & $\mathrm{AF}$ & 45 & 2.27 & [1.87-2.80] & & & \\
\hline FABP3 (ng/mL) & 6 months & Sinus & 281 & 30.86 & [25.62-38.45] & 0.597 & $(0.495-0.699)$ & 0.079 \\
\hline & & $\mathrm{AF}$ & 33 & 33.74 & {$[26.86-44.43$} & & & \\
\hline & 12 months & Sinus & 273 & 33.11 & [26.50-40.47] & 0.457 & $(0.359-0.554)$ & 0.380 \\
\hline & & AF & 44 & 30.37 & [24.61-39.34] & & & \\
\hline FGF23 (ng/mL) & 6 months & Sinus & 281 & 0.11 & [0.09-0.14] & 0.716 & $(0.625-0.807)$ & 0.001 \\
\hline & & $\mathrm{AF}$ & 33 & 0.15 & {$[0.12-0.19]$} & & & \\
\hline & 12 months & Sinus & 270 & 0.11 & [0.09-0.15] & 0.617 & $(0.525-0.708)$ & 0.019 \\
\hline & & AF & 44 & 0.14 & [0.10-0.18] & & & \\
\hline GDF15 (pg/mL) & 6 months & Sinus & 281 & 1058 & [791-1446] & 0.602 & $(0.493-0.712)$ & 0.067 \\
\hline & & $\mathrm{AF}$ & 33 & 1440 & [883-1715] & & & \\
\hline & 12 months & Sinus & 273 & 1140 & [812-1554] & 0.508 & $(0.416-0.599)$ & 0.870 \\
\hline & & $\mathrm{AF}$ & 44 & 1143 & [796-1598] & & & \\
\hline IGFBP7 (ng/mL) & 6 months & Sinus & 284 & 167.94 & [153.8-186.8] & 0.665 & $(0.564-0.766)$ & 0.004 \\
\hline & & $\mathrm{AF}$ & 34 & 187.07 & [164.6-230.4] & & & \\
\hline & 12 months & Sinus & 274 & 172.41 & [156.0-196.7] & 0.542 & $(0.450-0.634)$ & 0.380 \\
\hline & & $\mathrm{AF}$ & 45 & 174.74 & [159.8-210.4] & & & \\
\hline MYBPC3 (pg/mL) & 6 months & Sinus & 281 & 3.09 & [1.95-5.17] & 0.656 & $(0.559-0.753)$ & 0.006 \\
\hline & & AF & 33 & 4.62 & [2.63-9.87] & & & \\
\hline & 12 months & Sinus & 273 & 2.98 & [1.79-5.28] & 0.609 & $(0.524-0.695)$ & 0.028 \\
\hline & & $\mathrm{AF}$ & 44 & 4.00 & [2.48-6.68] & & & \\
\hline
\end{tabular}

Biomarker concentration at 6 and 12 months and results of ROC-analysis for discriminatory value to predict AF. P value from multiple testing by means of FDRcorrection. NT-proBNP-N-terminal pro-B type natriuretic peptide; Ang2-angiopoietin 2; BMP10—bone morphogenic protein-10; DKK3-Dickkopf-related protein-3; ESM1—endothelial cell specific molecule 1; FABP3 - fatty acid-binding protein C3; FGF23—fibroblast growth factor 23; GDF15 — growth differentiation factor-15; IGFBP7-insulin like growth factor-binding protein-7; MyBPC3-myosin binding protein 3 
Natriuretic peptides and Ang2 showed by far the largest significant increases in the patients with AF at 6 and 12 months $(\mathrm{P}<0.001)$ (Table 2$)$.

ROC analyses were done to assess the strength of the relation between biomarkers and ongoing AF (i.e. biomarkers assayed while an AF rhythm was recorded in a 12-lead ECG during a clinical visit). The AUCs were highest at 6 and 12 months, (Table 2) for total NTproBNP $\left(\mathrm{AUC}_{6 \mathrm{M}} 0.78\right.$ and $\mathrm{AUC}_{12 \mathrm{M}}$ 0.77), NT-proBNP $\left(\mathrm{AUC}_{6 \mathrm{M}} 0.87\right.$ and $\mathrm{AUC}_{12 \mathrm{M}} 0.86$ ), Ang2 (AUC ${ }_{6 \mathrm{M}} 0.73$ and $\mathrm{AUC}_{12 \mathrm{M}}$ 0.82); for BMP10 $\mathrm{AUC}_{6 \mathrm{M}}$ was 0.71 and $\mathrm{AUC}_{12 \mathrm{M}}$, 0.63. Multivariable logistic regression models estimated the association between these four biomarkers (total NT-proBNP, NT-proBNP, Ang2 and BMP10) with ongoing AF. The association was significant for all four after adjustment for clinical variables that were significant in univariable analysis (Table 3).

\section{Circulating biomarkers as predictors of $\mathrm{AF}$ recurrence} Total NT-proBNP, NT-proBNP, Ang2 and BMP10 were then included in analyses for the prediction of AF recurrence. In one year of follow-up, 203 patients (53.1\%) experienced at least one episode of AF recurrence, mostly identified in telemetric device recordings. Clinical characteristics and treatments of patients with at least one AF recurrence and with any recurrence were previously published [5] (see also Additional file 1: Table 1 Baseline clinical, eletrocardiographic and echocardiograpic characteristics of all patients and according to ongoing $\mathrm{AF}$ and AF recurrence). Males and patients with more than

Table 3 Biomarkers associated with ongoing atrial fibrillation

\begin{tabular}{|c|c|c|c|c|}
\hline \multirow[b]{2}{*}{ Biomarker } & \multicolumn{2}{|c|}{ Univariate model } & \multicolumn{2}{|c|}{ Multivariable model } \\
\hline & OR $(95 \% \mathrm{Cl})$ & $P_{\mathrm{fdr}}$ & OR $(95 \% \mathrm{Cl})$ & $P_{\mathrm{fdr}}$ \\
\hline $\begin{array}{l}\text { Total NT- } \\
\text { proBNP }\end{array}$ & $\begin{array}{l}1.70 \\
(1.32-2.19)\end{array}$ & $7.4 \times 10^{-5}$ & $\begin{array}{l}1.58 \\
(1.21-2.07)\end{array}$ & 0.001 \\
\hline NT-proBNP & $\begin{array}{l}2.19 \\
(1.66-2.88)\end{array}$ & $1.2 \times 10^{-7}$ & $\begin{array}{l}2.02 \\
(1.52-2.70)\end{array}$ & $8.0 \times 10^{-6}$ \\
\hline Ang2 & $\begin{array}{l}1.43 \\
(1.13-1.82)\end{array}$ & 0.004 & $\begin{array}{l}1.32 \\
(1.02-1.71)\end{array}$ & 0.034 \\
\hline BMP10 & $\begin{array}{l}1.60 \\
(1.23-2.09)\end{array}$ & $6.0 \times 10^{-4}$ & $\begin{array}{l}1.56 \\
(1.19-2.04)\end{array}$ & 0.001 \\
\hline
\end{tabular}

The association between biomarker concentration and AF during clinical visits was assessed by means of logistic regression models. The biomarker concentration was the value while AF was ongoing (i.e. if a patient presented AF at the six-month visit, the corresponding biomarker value was included while if the $\mathrm{AF}$ was present at 12 months that value was included). If no $\mathrm{AF}$ arose during visits, the baseline value was inserted. Data shown as odds ratio (OR) for an increment of 1 SD of baseline

Multivariable model was adjusted for: heart failure, $\mathrm{LVEF}<40 \%$ or both, history of hypertension and AF episode with LA dilatation. P-value was corrected for multiple testing by means of FDR-correction

NT-proBNP, N-terminal pro-B type natriuretic peptide; Ang2, angiopoietin 2; BMP10, bone morphogenic protein-10 two episodes of $\mathrm{AF}$ in the six months prior to inclusion in the study were more likely to suffer at least one AF recurrence.

Baseline concentrations of biomarkers in patients with or without AF recurrence were similar for all four biomarkers (Additional file 1: Table 3. Concentrations of circulating biomarkers at baseline in patients with or without AF recurrence). Kaplan Meier curves showing the incidence of AF recurrence in relation to the baseline biomarker concentration below or above the median indicate that curves started to diverge within the first week for total NT-proBNP, NT-proBNP and at one month for Ang2 and BMP10 (Fig. 1). Restricted cubic spline analysis showed linear associations for all four biomarkers with the recurrence of atrial fibrillation (Fig. 2), $\mathrm{p}>0.05$ for non-linearity. The predictive power for AF recurrence of baseline concentrations of total NTproBNP, NT-proBNP, Ang2, and BMP10 was assessed using Cox proportional hazard models. After adjustment for clinical variables only total NT-proBNP (HR 1.19, 95\%CI 1.04-1.36, $\left.\mathrm{p}_{\mathrm{fdr}}=0.026\right)$ and NT-proBNP (HR 1.19, $95 \%$ CI 1.06-1.36, $\left.\mathrm{p}_{\mathrm{fdr}}=0.016\right)$ significantly predicted AF recurrence (Table 4). The areas under the ROC curves based on the multivariate Cox models had a C-index of 0.822 for Total NT-proBNP and 0.829 for NT-proBNP, the difference was not statistically significant $(P=0.263)$ between the two models (Additional file 1: Fig. 1A ROC curves for first episode of recurrent atrial fibrillation. Curves are based on multivariable Cox survival model including standardized biomarkers - total-NT-proBNP and NT-proBNP - concentration). The risk of AF recurrence was analyzed in patients by quartiles of concentrations of the biomarkers at baseline. None of the quartiles were significantly different from the reference quartile after correction for multiple testing (Additional file 1: Table 4 Risk of AF recurrence for patients in the second, third and fourth quartiles of total-NT-proBNP, NTproBNP, Ang2, BMP10 concentrations, compared to the lowest quartile.).

\section{First hospitalization for $\mathrm{CV}$ reasons}

Total NT-proBNP was associated with first hospitalization for $\mathrm{CV}$ reasons in multivariable Cox proportional hazards regression analysis (HR 1.57; 95\%CI 1.29-1.90; $\left.\mathrm{p}_{\mathrm{fdr}}=1.2 \times 10^{-5}\right)$; the association in this analysis was also significant for NT-proBNP after adjusting for confounders, (HR 1.57; 95\%CI 1.34-1.84; $\mathrm{p}_{\mathrm{fdr}}=1.2 \times 10^{-6}$ ) and Ang2 (HR 1.34; 95\%CI 1.04-1.73; $\mathrm{p}=0.029$ ), but not for BMP10 (Table 5). The areas under the ROC curves based on the multivariate Cox models had a C-index of 0.725 for Total NT-proBNP and 0.742 for NT-proBNP, the difference was not statistically significant $(P=0.056)$ between the two models (Additional file 1: Fig. 1B ROC 


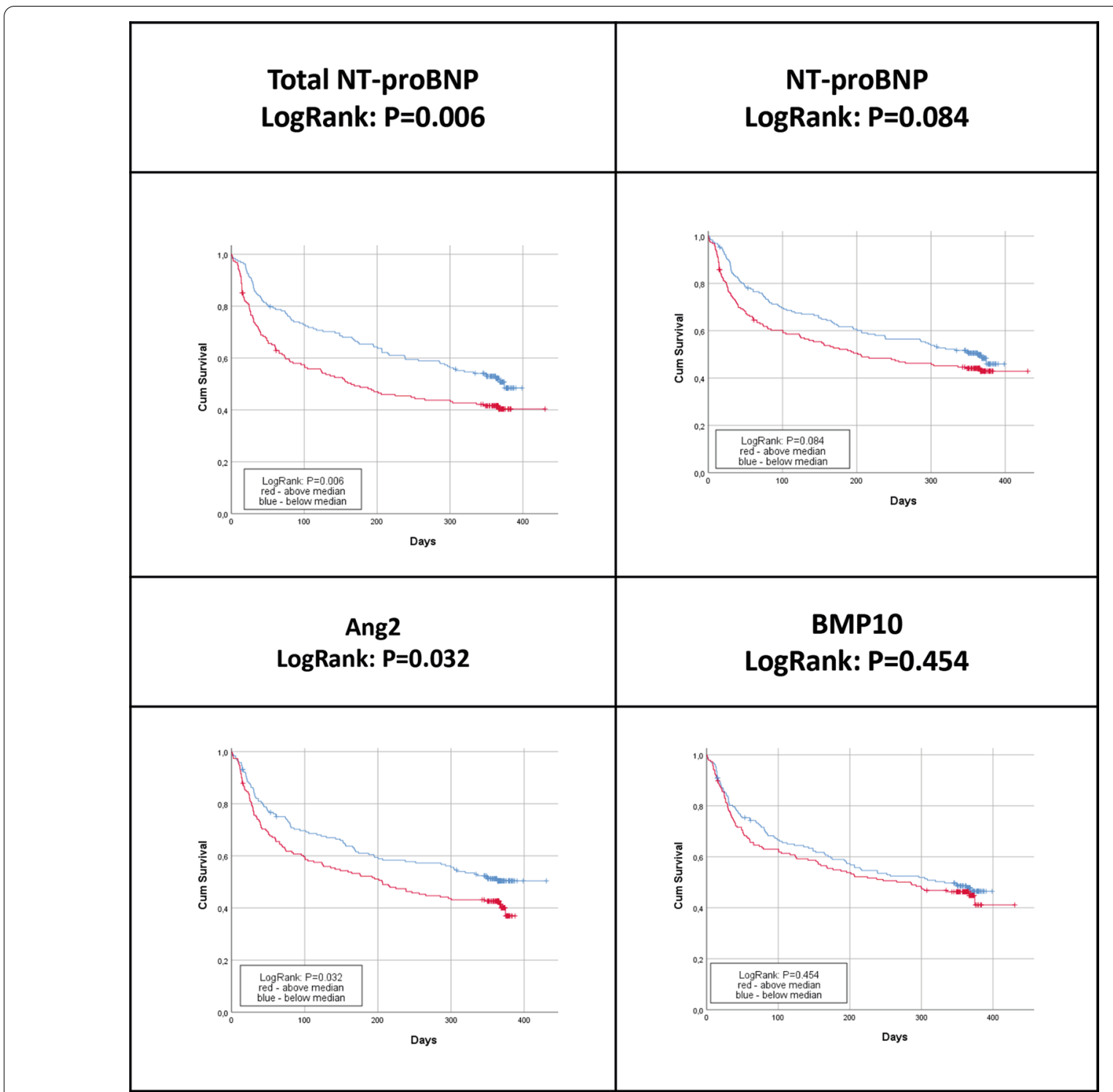

Fig. 1 Kaplan-Meier curves of first episode of AF recurrence by median baseline biomarker concentration. Log rank test for: Total NT-proBNP, $p=0.006 ;$ NT-proBNP, $p=0.084 ;$ Ang2, $p=0.032$ and BMP10, $p=0.454$

curves for first hospitalization for $\mathrm{CV}$ reasons. Curves are based on multivariable Cox survival model including standardized biomarkers - total-NT-proBNP and NTproBNP - concentration). The risk of first hospitalization for $\mathrm{CV}$ reasons was significantly higher only for patients in the fourth quartile of NT-proBNP compared to those in the lowest quartile (Additional file 1: Table 5 Risk for first hospitalization for $\mathrm{CV}$ reasons for patients in the second, third and fourth quartiles of total-NT-proBNP, NT-proBNP, Ang2, BMP10 concentrations, compared to the lowest quartile.).

\section{Discussion}

This study in patients in sinus rhythm but at risk of AF shows for the first time that the relationship of ongoing $\mathrm{AF}$ and the risk of first $\mathrm{AF}$ recurrence and first hospitalization for $\mathrm{CV}$ reasons with the novel biomarker total NT-proBNP is as strong as that of NT-proBNP. From the panel of biomarkers studied, also BMP10, a marker of cardiomyocyte growth in the myocardium of the right atrium and ventricle, and Ang2, involved in inflammation and coagulation, were associated with AF.

While the association of a biomarker with AF may give useful mechanistic insights on the disease, a biomarker that can tell the doctor in advance what is the risk of a 


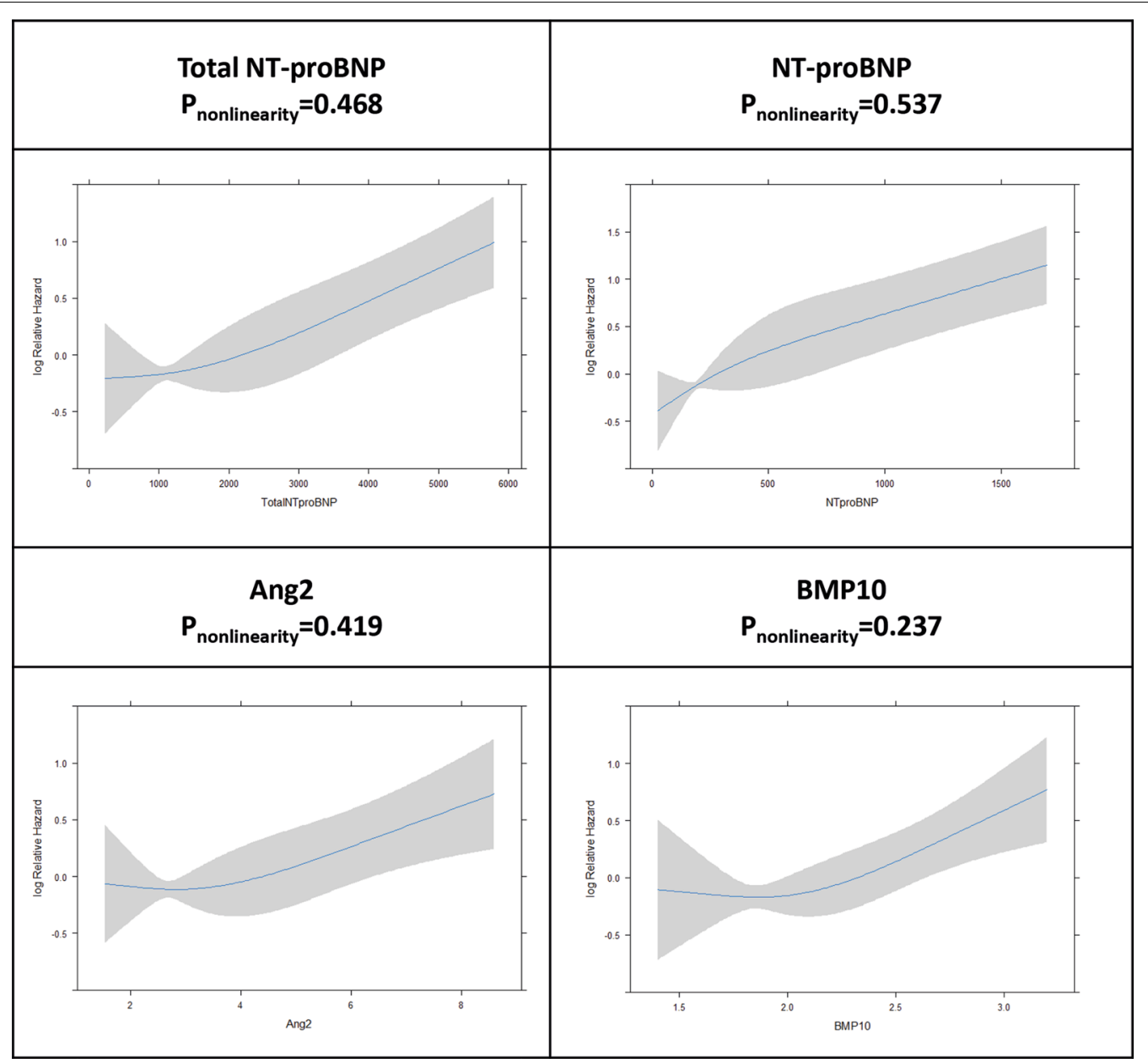

Fig. 2 Restricted cubic spline depicting the continuous biomarker concentrations in relation to the risk of time to first AF recurrence. The continuous line indicates the central log relative hazard and the shaded area the $95 \%$ confidence intervals. P value for non-linearity: Total NT-proBNP, $p=0.362 ;$ NT-proBNP, $p=0.798 ;$ Ang2, $p=0.827$ and BMP10, $p=0.364$

Table 4 Hazard ratios for atrial fibrillation recurrence according to candidate biomarkers

\begin{tabular}{llllll}
\hline Biomarker & \multicolumn{2}{l}{ Univariate model } & & \multicolumn{2}{l}{ Multivariable model } \\
\cline { 2 - 3 } \cline { 6 - 6 } & HR (95\%Cl) & $\mathbf{P}_{\text {fdr }}$ & & HR (95\%Cl) & $\mathbf{P}_{\text {fdr }}$ \\
\hline Total NT-proBNP & $1.15(1.02-1.30)$ & $\mathbf{0 . 0 4 0}$ & & $1.19(1.04-1.36)$ & $\mathbf{0 . 0 2 6}$ \\
NT-proBNP & $1.21(1.09-1.34)$ & $\mathbf{0 . 0 0 2}$ & & $1.19(1.06-1.35)$ & $\mathbf{0 . 0 1 6}$ \\
Ang2 & $1.15(1.01-1.30)$ & 0.047 & & $1.07(0.95-1.20)$ & 0.283 \\
BMP10 & $1.01(0.88-1.17)$ & $0.898 /$ & & $1.09(0.96-1.25)$ & 0.249
\end{tabular}

The prediction of AF recurrence was assessed by Cox proportional hazards regression models. Data shown as hazard ratio HR for an increment of 1 SD of baseline biomarker value. The multivariable model was adjusted for sex and $>2$ episodes of AF in the six months before inclusion in the GISSI-AF trial. P-value was corrected for multiple testing by means of FDR-correction. HR, hazard ratio; NT-proBNP, N-terminal pro-B type natriuretic peptide; Ang2, angiopoietin 2; BMP10, bone morphogenic protein-10
Table 5 Hazard ratios for first hospitalization for CV reasons

\begin{tabular}{|c|c|c|c|c|}
\hline \multirow[t]{2}{*}{ Biomarker } & \multicolumn{2}{|c|}{ Univariate model } & \multicolumn{2}{|c|}{ Multivariable model } \\
\hline & $\mathrm{HR}[95 \% \mathrm{Cl}]$ & $P_{f d r}$ & $\mathrm{HR}[95 \% \mathrm{Cl}]$ & $P_{\text {fdr }}$ \\
\hline $\begin{array}{l}\text { Total NT- } \\
\text { proBNP }\end{array}$ & $\begin{array}{l}1.54 \\
(1.30-1.83)\end{array}$ & $1.9 \times 10^{-6}$ & $\begin{array}{l}1.57 \\
(1.29-1.90)\end{array}$ & $1.2 \times 10^{-5}$ \\
\hline NT-proBNP & $\begin{array}{l}1.49 \\
(1.31-1.70)\end{array}$ & $5.6 \times 10^{-9}$ & $\begin{array}{l}1.57 \\
(1.34-1.84)\end{array}$ & $1.2 \times 10^{-6}$ \\
\hline Ang2 & $\begin{array}{l}1.31 \\
(1.08-1.59)\end{array}$ & 0.007 & $\begin{array}{l}1.34 \\
(1.04-1.73)\end{array}$ & 0.029 \\
\hline BMP10 & $\begin{array}{l}1.38 \\
(1.10-1.74)\end{array}$ & 0.007 & $\begin{array}{l}1.25 \\
(0.96-1.63)\end{array}$ & 0.097 \\
\hline
\end{tabular}

The prediction of cardiovascular hospitalization was assessed by Cox proportional hazards regression. Data shown as hazard ratio HR for an increment of $1 \mathrm{SD}$ of baseline biomarker concentration. The multivariable model was adjusted for systolic blood pressure, history of hypertension, peripheral artery disease and smoking. P-value was corrected for multiple testing by means of FDR-correction. HR, hazard ratio; NT-proBNP, N-terminal pro-B type natriuretic peptide; Ang2, angiopoietin 2; BMP10, bone morphogenic protein-10 
patient having new episodes of AF, is clinically important. That is why we assessed, for the first time, the association and the predictive power for AF of the plasma concentrations of total NT-proBNP in a cohort of patients with a history of AF, in sinus rhythm, at high risk of AF recurrence.

We hypothesized that the accuracy and prognostic value of NT-proBNP would improve using a biomarker to identify the glycosylated NT-proBNP. This task by itself is challenging, given the repeatedly reported superiority of NT-proBNP [7]. In fact, we did see that both total NT-proBNP and NT-proBNP gave significant and similar results for predicting AF. The median total NTproBNP plasma concentration was 6.6, 7.2 and 6.8 times higher than NT-proBNP at baseline and at six- and 12-months follow-up (Table 1 and 2). The wide interindividual variability in the ratio (e.g. 0.57 to 42.05 ) justifies the search for associations of total NT-proBNP and AF or clinical events. This indicated that in patients in sinus rhythm with a recent history of AF, NT-proBNP is extensively glycosylated and the extent of glycosylation does not change over time. In patients with acute dyspnea, and using deglycosylation enzymes to identify total NT-proBNP, Røsjø et al. [18] reported nearly double the levels of total NT-proBNP than NT-proBNP in HF and non-HF patients. At a median of 816 days, both natriuretic peptides were associated with all-cause mortality risk in HF patients; for the deglycosylated total NT-proBNP concentration the HR [95\%CI] was 1.42 [1.24-1.63], $\mathrm{p}<0.001$, and for NT-proBNP 1.29 [1.131.46], $\mathrm{p}<0.001$. In the present study only 42 patients had clinically diagnosed HF or LVEF $<40 \%$ (11\%); this small number does not permit analysis of AF stratified by HF, although the incidence of AF recurrence was no different in patients with HF (12.3\%) and those without (9.5\%, $\mathrm{p}=0.38$ ). Nonetheless, circulating biomarkers were significantly higher in patients with HF, independently of AF. The only exception was BMP10, apparently independent of HF (Additional file 1: Table 6 Concentrations of circulating biomarkers in patients with and without clinical HF or LVEF $<40 \%$ ).

Ang2 showed a strong association with AF, confirming the pathogenic role of inflammatory activation in $\mathrm{AF}$ [19]; however, Ang2 had no predictive power for recurrent AF. In the GISSI-AF sub-study, similar results were reported for two other inflammatory markers, IL6 and hsCRP [6]. Like for Ang2 these two biomarkers were not independent predictors of AF recurrence.

In relation to $\mathrm{AF}$, another marker closely involved in inflammations-GDF15-performed poorly in the present study. However, the ARISTOTLE large-scale trial reported GDF15 as a risk factor for major bleeding, mortality, and stroke in patients with permanent AF [20].
Very recently, in 359 patients after catheter ablation, BMP10 was an independent predictor of AF recurrence while NT-proBNP was not [16]. However, those patients were more severely ill than those in the present study ( $47 \%$ had HF and $12 \%$ a history of stroke; NT-proBNP approximately double), and absolute concentrations of BMP10 were only slightly higher.

Recently natriuretic peptides, particularly NT-proBNP, have been reported to be associated with inflammation [21]. This suggests a common pathophysiological mechanism for the biomarkers assessed in this study that were associated with AF.

\section{Strengths and limitations of the study}

The main strengths of this study are: (a) it was a multicenter randomized clinical trial with concomitant serial echocardiography and circulating biomarkers analyzed centrally; and (b) trans-telephonic electrocardiographic monitoring enabled us to record and identify AF recurrence efficiently during the 12-month follow-up. Another strength is the simultaneous analysis of total NT-proBNP with other biomarkers involved in different pathophysiological mechanisms, some of them assessed for the first time for $\mathrm{AF}$ diagnosis or as predictors of $\mathrm{AF}$ recurrence (Ang2, BMP10). The potential added value of total NTproBNP to the benchmark biomarker NT-proBNP was assessed from different dimensions of performance, as recently proposed for the evaluation of new biomarkers [20].

Our results cannot apply to all patients with AF since at baseline the GISSI-AF patients were in sinus rhythm and had a lower rate of co-morbidities than patients with $\mathrm{AF}$ in real life or in other cohorts with a higher frequency of persistent or permanent $\mathrm{AF}[1,2,18]$. This was due to compliance with the strict eligibility criteria of the trial. The mean CHADS2 modified score was indeed very low, averaging $1.41 \pm 0.84$ in the whole population, compatible with the low morbidity rate of the patients selected [22]. The low frequency of deaths after 12 months (only one) and thromboembolic events (three) in the GISSIAF sub-study could not be considered for the outcome analysis. The small number of patients with ongoing AF at a follow-up visit is a limitation for the association of the biomarkers with the diagnosis of AF.

\section{Conclusions}

Total NT-proBNP performs similarly and is strongly correlated to NT-proBNP as a biomarker in AF. Total NT-proBNP and NT-proBNP were both significantly associated with an increased risk for first AF recurrence and first hospitalization for $\mathrm{CV}$ reasons. Ang2 and BMP10 were significantly associated with ongoing AF, pointing to a pathogenic role of cardiac extracellular 
matrix and cardiomyocyte growth in the myocardium of the right atrium and ventricle.

\begin{abstract}
Abbreviations
Ang2: Angiopoietin 2; BMP10: Bone morphogenic protein-10; CV: Cardiovascular; DKK3: Dickkopf-related protein 3; ELISA: Enzyme-linked immuno-sorbent assay; ESM1: Endothelial cell specific molecule 1; FABP3: Fatty acid binding protein 3; FGF23: Fibroblast growth factor 23; GDF15: Growth differentiation factor-15; HF: Heart failure; IGFBP7: Insulin-like growth factor-binding protein-7 (IGFBP7); MyBPC3: Myosin binding protein C3; NT-proBNP: N-terminal pro-B type natriuretic peptide.
\end{abstract}

\section{Supplementary Information}

The online version contains supplementary material available at https://doi. org/10.1186/s12872-021-02358-y.

Additional file 1. Appendix 1 Detection of recurrent AF during follow-up. Appendix 2 Assays of circulating biomarkers and detection of recurrent AF during follow-up. Appendix 3 Participating centers and investigators. Table 1 Baseline clinical, eletrocardiographic and echocardiograpic characteristics of all patients and according to ongoing AF and AF recurrence. Table $\mathbf{2}$ Correlation coefficients for biomarker concentrations at baseline.Table $\mathbf{3}$ Concentrations of circulating biomarkers at baseline in patients with or without AF recurrence. Table 4 Risk of AF recurrence for patients in the second, third and fourth quartiles of total-NT-proBNP, NT-proBNP, Ang2, BMP10 concentrations, compared to the lowest quartile. Table $\mathbf{5}$ Risk for first hospitalization for $\mathrm{CV}$ reasons for patients in the second, third and fourth quartiles of total-NTproBNP, NT-proBNP, Ang2, BMP10 concentrations, compared to the lowest quartile. Table 6 Concentrations of circulating biomarkers in patients with and without clinical HF or LVEF $<40 \%$. Fig. 1A ROC curves for first episode of recurrent atrial fibrillation. Curves are based on multivariable Cox survival model including standardized biomarkers total-NT-proBNP and NT-proBNP concentration. Fig. 1B ROC curves for first hospitalization for $\mathrm{CV}$ reasons. Curves are based on multivariable Cox survival model including standardized biomarkers total-NT-proBNP and NT-proBNP concentration.

\section{Acknowledgements}

We thank the patients, nurses and cardiologists who participated in the biohumoral substudy of GISSI-AF trial. We are grateful to Judith Baggott for language editing, Simona Barlera and Adriana Blanda for contributing to the statistical analysis.

\section{Authors' contributions}

LS, JM and RL had full access to all the data in the study and take responsibility for its integrity and the accuracy of data analysis. Study concept and design: RL and LS. Data acquisition, analysis or interpretation: LS, JM and RL. Drafting the manuscript: LS, RL and JM. Critical revision of the manuscript for important intellectual content: LS, JM, SM, DN, MD, APM, GT, MGF, DL, UHW-T and RL. Statistical analysis: JM. All authors had full access to all data and take responsibility for the integrity and accuracy of the data analysis. All authors contributed to revision of the manuscript and accepted the final version.

\section{Funding}

The GISSI studies and this substudy are supported by the Associazione Nazionale Medici Cardiologi Ospedalieri and by the Istituto di Ricerche Farmacologiche Mario Negri IRCCS. Novartis Pharma Italy funded the GISSI-AF trial. The substudy was partially supported by Roche Diagnostics GmbH, Penzberg, Germany. The funders had no role in the design and conduct of the study; data collection, management, analysis and interpretation; preparation, review or approval of the manuscript; and the decision to submit the manuscript for publication.

\section{Availability of data and materials}

The data are stored at the GISSI-AF Coordinating Centers (Florence and Milan). Data are available upon justified request to the GISSI-AF trial Steering Committee.

\section{Declarations}

\section{Ethics approval and consent to participate}

The GISSI-AF trial complied with all the relevant national regulations, and with the Declaration of Helsinki. The study was conducted with the approval of the local ethics committees from the 36 Italian clinical centers that participated in the biomarkers and echocardiographic substudy of the GISSI-AF trial (Additional file 1: Appendix 3 Participating centers and investigators). All participants provided written informed consent.

\section{Consent for publication}

Not applicable.

\section{Competing interests}

$L S, A P M, M G F, M D, D L, G T$ and $R L$ received institutional research support from Novartis Pharma and Roche Diagnostics. JM and DN received institutional research support from Roche Diagnostics. UHW-T is an employee of Roche Diagnostics $\mathrm{GmbH}$, Penzberg, Germany, the company that funded part of the present study. SM is currently an employee at Roche Diagnostics International, Rotkreuz, Switzerland.

\section{Author details}

${ }^{1}$ Department of Cardiovascular Medicine, Istituto Di Ricerche Farmacologiche Mario Negri IRCCS, Via Mario Negri 2, 20156 Milan, Italy. ${ }^{2}$ Roche Diagnostics GmbH, Penzberg, Germany. ${ }^{3}$ Healthcare Research and Innovation Program, IRCS-HTA, BK Foundation, Trento, Italy. ${ }^{4}$ ANMCO Research Center, Florence, Italy. ${ }^{5}$ Roche Diagnostics International Ltd, Rotkreuz, Switzerland. ${ }^{6}$ Istituto Di Anestesia E Rianimazione, Università Degli Studi Di Milano, Ospedale Maggiore, Istituto Di Ricovero E Cura a Carattere Scientifico, Milan, Italy.

Received: 24 May 2021 Accepted: 2 November 2021

Published online: 19 November 2021

\section{References}

1. Chugh SS, Havmoeller R, Narayanan K, et al. Worldwide epidemiology of atrial fibrillation: a Global Burden of Disease 2010 Study. Circulation. 2014;129:837-47. https://doi.org/10.1161/CIRCULATIONAHA.113.005119.

2. Kirchhof P, Benussi S, Kotecha D, et al. 2016 ESC guidelines for the management of atrial fibrillation developed in collaboration with EACTS. Rev Esp Cardiol (Engl Ed). 2017;70:50. https://doi.org/10.1016/j.rec.2016.11. 033.

3. Chang K-W, Hsu JC, Toomu A, et al. Clinical applications of biomarkers in atrial fibrillation. Am J Med. 2017;130:1351-7. https://doi.org/10.1016/j. amjmed.2017.08.003.

4. Chua W, Purmah Y, Cardoso VR, et al. Data-driven discovery and validation of circulating blood-based biomarkers associated with prevalent atrial fibrillation. Eur Heart J. 2019;40:1268-76. https://doi.org/10.1093/eurhe artj/ehy815.

5. Latini R, Masson S, Pirelli S, et al. Circulating cardiovascular biomarkers in recurrent atrial fibrillation: data from the GISSI-atrial fibrillation trial. J Intern Med. 2011;269:160-71. https://doi.org/10.1111/j.1365-2796.2010. 02287.x.

6. Masson S, Aleksova A, Favero C, et al. Predicting atrial fibrillation recurrence with circulating inflammatory markers in patients in sinus rhythm at high risk for atrial fibrillation: data from the GISSI atrial fibrillation trial. Heart. 2010;96:1909-14. https://doi.org/10.1136/hrt.2009.191460.

7. Staerk L, Preis $S R$, Lin $H$, et al. Protein biomarkers and risk of atrial fibrillation: the FHS. Circ Arrhythm Electrophysiol. 2020;13: e007607. https://doi. org/10.1161/CIRCEP.119.007607.

8. Levin ER, Gardner DG, Samson WK. Natriuretic peptides. N Engl J Med. 1998;339:321-8. https://doi.org/10.1056/NEJM199807303390507. 
9. Goetze JP, Christoffersen C, Perko M, et al. Increased cardiac BNP expression associated with myocardial ischemia. FASEB J. 2003;17:1105-7. https://doi.org/10.1096/fj.02-0796fje.

10. Goetze JP, Bruneau BG, Ramos HR, et al. Cardiac natriuretic peptides. Nat Rev Cardiol. 2020. https://doi.org/10.1038/s41569-020-0381-0.

11. Halfinger B, Hammerer-Lercher A, Amplatz B, et al. Unraveling the molecular complexity of O-glycosylated endogenous ( $\mathrm{N}$-terminal) proB-type natriuretic peptide forms in blood plasma of patients with severe heart failure. Clin Chem. 2017;63:359-68. https://doi.org/10.1373/clinc hem.2016.265397.

12. Luckenbill KN, Christenson $\mathrm{RH}$, Jaffe AS, et al. Cross-reactivity of BNP, NT-proBNP, and proBNP in commercial BNP and NT-proBNP assays: preliminary observations from the IFCC Committee for Standardization of Markers of Cardiac Damage. Clin Chem. 2008;54:619-21. https://doi.org/ 10.1373/clinchem.2007.097998

13. Saenger AK, Rodriguez-Fraga $O$, Ler $R$, et al. Specificity of B-type natriuretic peptide assays: cross-reactivity with different BNP, NT-proBNP, and proBNP peptides. Clin Chem. 2017;63:351-8. https://doi.org/10.1373/ clinchem.2016.263749.

14. Disertori M, Latini R, Maggioni AP, et al. Rationale and design of the GISSI-Atrial Fibrillation Trial: a randomized, prospective, multicentre study on the use of valsartan, an angiotensin II AT1-receptor blocker, in the prevention of atrial fibrillation recurrence. J Cardiovasc Med (Hagerstown). 2006;7:29-38. https://doi.org/10.2459/01.JCM.0000199778.85343.08.

15. Investigators GISSI-AF, Disertori M, Latini R, et al. Valsartan for prevention of recurrent atrial fibrillation. N Engl J Med. 2009;360:1606-17. https://doi. org/10.1056/NEJMoa0805710.

16. Reyat JS, Chua W, Cardoso VR, et al. Reduced left atrial cardiomyocyte PITX2 and elevated circulating BMP10 predict atrial fibrillation after ablation. JCI Insight. 2020. https://doi.org/10.1172/jci.insight.139179.
17. Latini R, Masson S, Anand IS, et al. Prognostic value of very low plasma concentrations of troponin $\mathrm{T}$ in patients with stable chronic heart failure. Circulation. 2007;116:1242-9. https://doi.org/10.1161/CIRCULATIONAHA. 106.655076.

18. Røsjø H, Dahl MB, Jørgensen $M$, et al. Influence of glycosylation on diagnostic and prognostic accuracy of $\mathrm{N}$-terminal pro-B-type natriuretic peptide in acute dyspnea: data from the Akershus Cardiac Examination 2 Study. Clin Chem. 2015;61:1087-97. https://doi.org/10.1373/clinchem. 2015.239673.

19. Scholz A, Plate KH, Reiss Y. Angiopoietin-2: a multifaceted cytokine that functions in both angiogenesis and inflammation. Ann N Y Acad Sci. 2015;1347:45-51. https://doi.org/10.1111/nyas.12726.

20. Wallentin L, Hijazi Z, Andersson U, et al. Growth differentiation factor 15, a marker of oxidative stress and inflammation, for risk assessment in patients with atrial fibrillation: insights from the Apixaban for Reduction in Stroke and Other Thromboembolic Events in Atrial Fibrillation (ARISTOTLE) trial. Circulation. 2014;130:1847-58. https://doi.org/10.1161/CIRCU LATIONAHA.114.011204.

21. Fish-Trotter H, Ferguson JF, Patel N, et al. Inflammation and circulating natriuretic peptide levels. Circ Heart Fail. 2020;13: e006570. https://doi. org/10.1161/CIRCHEARTFAILURE.119.006570.

22. Disertori M, Franzosi MG, Barlera S, et al. Thromboembolic event rate in paroxysmal and persistent atrial fibrillation: data from the GISSIAF trial. BMC Cardiovasc Disord. 2013;13:28. https://doi.org/10.1186/ 1471-2261-13-28.

\section{Publisher's Note}

Springer Nature remains neutral with regard to jurisdictional claims in published maps and institutional affiliations.
Ready to submit your research? Choose BMC and benefit from:

- fast, convenient online submission

- thorough peer review by experienced researchers in your field

- rapid publication on acceptance

- support for research data, including large and complex data types

- gold Open Access which fosters wider collaboration and increased citations

- maximum visibility for your research: over $100 \mathrm{M}$ website views per year

At BMC, research is always in progress.

Learn more biomedcentral.com/submissions 